\title{
Torakolomber omurga kırıklarında konservatif yaklaşımlar
}

\section{Conservative treatment options for thoracolumbar vertebra fractures}

\author{
Burak Akesen, Ali Özyalçın \\ Uludağ Üniversitesi Tıp Fakültesi, Ortopedi ve Travmatoloji Anabilim Dalı, Bursa
}

\begin{abstract}
Torakolomber omurga kırıklarında cerrahi ve konservatif tedavi seçenekleri arasında hangisinin üstün olduğu konusunda tam bir fikir birliği sağlanmamıştır. Bu derlemenin amacı, günümüze kadar yapılan geniş kapsamlı çalışmalardan yola çıkarak torakolomber omurga kırıklarında tedaviler arası başarı farklarını ortaya koymaktır. Yirmi altı yıllık bir süreç içerisinde yapılmış olan geniş kapsamlı ve güncel yayınlar PubMed (MEDLINE)'de taranmıştır. Yayınlar, travmaya bağlı gelişmiş torakolomber omurga kırıkları üzerinde son 26 yılda yapılan çalışmalardan seçilmiştir. Seçme kriterleri, travmatik bir mekanizma ve torasik veya lomber omurga kırıklarından kaynaklanan burst kırıklarından oluşuyordu. Patolojik omurga kırıkları, osteoporoza bağIı gelişen omurga kırıkları ve servikal omurga kırıkları üzerine yapılan çalışmalar derlemeye dahil edilmemiştir. Toplam 49 adet yayın incelenmiştir. Yayınların iki adedi Seviye I, yedi adedi Seviye II kanıt derecesindedir. Bu çalışma, burst kırığı hastalarını inceleyen, hem klinik hem de radyolojik yan etkileri hesaba katan, erken ve geç takip hasta sonuçlarını rapor eden en büyük çalışmalardan biridir. Torakolomber omurga kırıklarında konservatif yaklaşım, hastanın klinik durumuna, beklentisine, doktorun tecrübesine ve tedavi imkanlarına göre uygulanmaktadır. Stabil omurga kırıklarında altın standart tedavi hakkında fikir birliği halen oluşmamıştır. Yayınların çoğunda nörolojik defisit olan hastalar çalışma dışı bırakılmış olup geri kalan hastalarda fonksiyonel iyileşme ile radyolojik iyileşmeler arasında bir korelasyon gösterilememiştir. Cerrahi veya konservatif yaklaşımlarda başarı oranı benzer bulunmuştur.
\end{abstract}

Anahtar sözcükler: torakolomber omurga; omurga kırıkları; konservatif tedavi; cerrahi tedavi; cerrahi tedavi ve konservatif tedavi başarı oranları; altın standart; burst kırığı
Gold standard treatment choice for thoracolumbar fractures is still unclear. The purpose of this paper is to review the results of conservative treatment options for thoracolumbar vertebra fractures. A comprehensive search of the English literature over the past 26 years was conducted using PubMed (MEDLINE). Comprehensive and up to date studies including these 26 years have been reviewed. The inclusion criteria consisted of burst fractures resulting from a traumatic mechanism, and fractures of the thoracic or lumbar spine. The exclusion criteria consisted of osteoporotic burst fractures, pathological burst fractures, and fractures located in the cervical spine. We have examined 2 Level I, 7 Level II, total 49 studies. This is one of the largest studies examining burst fracture patients, adjusting for both clinical and radiologic confounders and reporting patient outcomes with early and late follow up. The conservative management of thoracolumbar spine fractures is based on the patient's clinical condition, expectations, the experience of the physician, and treatment options. There is still no consensus on gold standard treatment for stable spinal fractures. In most of the publications, patients with neurological deficit were excluded from the study and no correlation was found between the functional recovery and radiological improvements in the remaining patients. No differences were found in outcomes between patients treated either surgically or nonsurgically.

Key words: thoracolumbar vertebra; spine fractures; vertebra fractures; conservative treatment; surgery; differences between surgery and conservative treatment; gold standard; burst fracture
T orakolomber omurgalarda gelişen kırıklar, omurga travması sonrasında en sık görülen omurga kırıklarıdır. Kırıklara yaklaşım posterior redüksiyon ve ortezleme etrafında döner. Çok sık olmasına rağmen, kriter farklııkları, cerrahların tecrübe ve görüşleri, operasyon endikasyonlarının net olmaması, konservatif tedavideki iyileşme süreci, yaklaşımlar sırasında alınan riskler nedeniyle, altın standart tedavi yaklaşımları netleşmemiştir. ${ }^{[1-4]}$
Ortezleme ve posterior redüksiyon yöntemleri Hippocrates tarafından yüzlerce yıl önce tanımlanmıştır. Fakat bu konudaki gelişmeler son 30 yılda dramatik olarak değişmiştir. Cerrahi olarak enstrümantasyonun ve omurga cerrahlarının yaygınlaşması ile yaklaşımlar, görüşler hızla değişmiş, tedavi kriterleri artmıştır. Cerrahi seçeneği popüler hale gelmiş olup bu gelişmeler ile birlikte kırıkların ne zaman ve nasıl cerrahi stabilizasyona ihtiyaç duyacağı konusunda fazla sayıda çalışma yapıımıştır.

- Illetişim adresi: Doç. Dr. Burak Akesen, Uludağ Üniversitesi Tıp Fakültesi, Ortopedi ve Travmatoloji Anabilim Dalı, Bursa Tel: 0530 - 5103235 e-posta: burakakesen@hotmail.com

- Geliș tarihi: 1 Kasım $2018 \quad$ Kabul tarihi: 1 Kasım 2018 
Torakolomber omurga kırıkları genellikle kompresyon-fleksiyon, distraksion ve kırıklı çıkığa bağlıdır; kırıkların geneli (\%60) ise, torakal kifoz ile lomber lordozun birleştiği torakolomber birleşkede meydana gelir. Hiperfleksiyonda zorlamaya bağlı kompresyon kırıkları genellikle stabil kabul edilmektedir. Bu tarz travmalarda anterior kolonda kırık gelişmekte posterior bağ ve posterior kolon ise sağlam kalmaktadır. Torakal omurgalarda ise, kostalar sayesinde oluşturulan kafes stabiliteye destek olur. Bu kısmi stabilizasyon etkenleri kırıklara yaklaşım stratejisinde değişkenliğe yol açmaktadır.

Stabil olmayan omurga kırıklarında tercih cerrahiden yanadır. Bu nedenle orta kolon kırıklarında, posterior ligamentöz kompleks hasarlanmasında ve nörolojik defisit varlığında cerrahi yaygın olarak tercih edilmektedir. Stabil kırıklarda cerrahi ve konservatif yaklaşım arasında uzun dönem iyileşme, klinik ve fonksiyonel olarak ele alındığında kesin bir fark gösterilememekle birlikte, cerrahi maliyetleri ve komplikasyonları açısından dezavantajlı durumdadır. Radyolojik olarak değerlendirildiğinde ise, cerrahi sonrası görüntülemeler konservatif yaklaşımdan üstün başarı göstermektedir. Ancak bu avantajın klinik olarak bir bağlantısı gösterilememiştir.

Konservatif yaklaşım olarak çokça seçilen seçenekler, torakolomber omurga kırıklarında; minimal ortezler (lumbosakral ortez), tek bir düzlemde hareketi kısıtlayan ortezler (Jewett brace gibi), çok düzlemde omurganın hareketini kısıtlayan ortezler (tamamen vücuda oturan ve hasta için özel üretim ortezler), hiperekstansiyon redüksiyonu ve buna yönelik uygulamalar şeklinde özetlenebilir. Ortezlemede dezavantajlı taraf, bazı çalışmalarda ortezle takip sırasında gelişen nörolojik muayenedeki bozulmadır. Klinik olarak nörolojik durumdaki bozulma her ne kadar ortezlemenin uzun süre takiplerinde ortaya çıkmakta ve dezavantaj olarak geçmekte ise de, genel görüş gerçek stabil omurga kırıklarında daha sonra gelişen nörolojik bozulma oranları arasında fark olmadığı yönündedir. Ancak, bir omurga kırığının gerçekten stabil olduğunu anlayabilmek için posterior ligamentöz kompleks gibi yapıların değerlendirmesinde manyetik rezonans (MR) görüntüleme önemli bir tanı yöntemi iken, çoğu yayında MR ile değerlendirme çalışma dışında bırakılmış veya stabilitede bir kriter olarak kabul edilmemiştir (Tablo 1).

\section{METOD}

Yazım kuralları Biomedical Journals - International Committee of Medical Journal Editors (http://www.icmje.org) ile uyumlu olup, çalışmanın yapıldığı dökümanlar PubMed Database (MEDLINE)'den alınmıştır. Database'de yapılan aramalarda anahtar kelimeler olarak "spine AND burst", "burst fracture", "burst AND fracture","thoracolumbar fracture", "Nonoperative treatment", "conservative treatment" seçilmiştir. Yaklaşık 26 yıllık (1992-2018) bir süreç içerisindeki torakolomber omurga kırıklarında cerrahi yaklaşım ve konservatif yaklaşımları ele alan yayınlar incelenmiştir. Kırık oluşma şekli olarak travma seçilmiş olup torakal ve lomber bölge dışı omurga kırıkları, osteoporotik vertebra kırıkları, patolojik kırıklar incelenen yayınlarda çalışma dışında bırakılmıştır. İncelenen çalışmaların çoğu geriye dönük çalışmalar olup hastalar randomize kontrollü olarak seçilmiştir. Bu çalışma olgu-kontrol, olgu sunumları, olgu serileri, karşılaştırmalı çalışmalar, geriye dönük kohort çalışmalar ve derlemeler gibi çalışmalardan oluşturulmuştur. Çalışmaların kanıt seviyeleri "Oxford Centre of Evidence Based Medicine Levels of Evidence" tarafindan oluşturulan tabloya göre belirlenmiştir (Tablo 2).

\section{SONUÇ}

Yirmi altı yıllık bir süreç içerisinde yazılmış toplam 71 adet çalışma incelenmiş olup 49 çalışma derlemeye dahil olma kriterlerini sağlamaktadır. Kanıt seviyesine göre incelendiğinde iki adet Seviye I, yedi adet Seviye II ve kırk adet seviyesi net olmayan veya Seviye III'ün altında yayın değerlendirilmiştir (Şekil 1).

Torakolomber omurga kırıkları ile ilgilenen cerrah sayısı çok fazladır. Bu nedenle çok sayıda yayın ve olgu serisi mevcuttur. Bu konuda kanıt seviyesi yüksek yayınlar kadar, kanıt seviyesi düşük ancak çok sayıda yapılmış olan olgu serileri ve bu olgu serilerinin uzun dönem takipleri de önemlidir. Seviye III ve altı yayınlar ele alındığında pek çok olgu aynı konservatif tedavi şekilleri ve cerrahi seçenekleri ile takip edilmiştir. Olgu serilerinin bir senelik takiplerle yapılmış olması ve bu takiplerde hemen hepsinde aynı ağrı skorlaması kullanılmış olması, bu yayınların derlenmesini değerli hale getirmektedir.

Yayınlarda tedavi başarısını ölçmek için; Visual Analog Scale (VAS), 36-Item Short Form Health Survey (SF-36), Oswestry Disability Index (ODI) ve Roland Morris Disability Questionnaire skorlamaları kullanılmıştır.

Fonksiyonel ve radyolojik olarak farklı sonuçlar bulunmuş olsa da aradaki fark tedavi seçeneklerinde bir altın standart oluşturmaya yetmemiştir. Klinik olarak ağrı skorlamalarında küçük farklılıklar gözlenmiş olmasına rağmen, fonksiyonel olarak hastaların bir yıllık takiplerinde ağrılarında, gelişen komplikasyon oranlarında ve işe dönme zamanlarında ağrı skorlamaları ölçüt kabul edildiğinde, orantılı bir fark elde edilememiştir. Bu nedenle, elde edilen küçük farklar anlamlı kabul edilmemektedir. Radyolojik değerlendirme ise 
Tablo 1. Seviye I-II kanıt derecesinde yapılmış olan torakolomber omurga kırıklarına konservatif yaklaşımı değerlendiren yayınlar

\begin{tabular}{|c|c|c|c|c|c|c|c|}
\hline $\begin{array}{l}\text { Yazarlar } \\
\text { ve yılları }\end{array}$ & $\begin{array}{l}\text { Kanıt } \\
\text { seviyesi }\end{array}$ & $\begin{array}{l}\text { Çalışma } \\
\text { planı }\end{array}$ & $\begin{array}{l}\text { Takip } \\
\text { yılı }\end{array}$ & $\begin{array}{l}\text { Çalışma } \\
\text { grubu }\end{array}$ & Tedavi & $\begin{array}{l}\text { Fonksiyonel } \\
\text { sonuçlar }\end{array}$ & $\begin{array}{l}\text { Radyolojik } \\
\text { sonuçlar }\end{array}$ \\
\hline $\begin{array}{l}\text { Siebanga } \\
\text { ve ark.[5] } \\
2006\end{array}$ & 1 & $\begin{array}{l}\text { Ileriye dönük } \\
\text { Geriye dönük } \\
\text { Kohort } \\
32 \text { olgu }\end{array}$ & 4,3 yıl & $\begin{array}{l}\text { T10-L4 omurga kırıkları, } \\
\text { AO A1 tip, A2 tip, A3 tip } \\
\text { nörolojik defisiti olmayan } \\
\text { omurga kırıkları, } \\
18-60 \text { yaş arası hastalar. }\end{array}$ & $\begin{array}{l}\text { Kısa segment posterior } \\
\text { enstrümantasyon ve } \\
\text { Jewett hiperekstansion } \\
\text { ortezi (A) ile } \\
\text { Yalnızca Jewett } \\
\text { hiperekstansion ortezi } \\
\text { (B) }\end{array}$ & $\begin{array}{l}\text { VAS ağrı skorunda farklılık-A: } \\
\text { 87/B: } 72 \\
\text { RMDQ skoru-A: 3,1/B: 8,9 } \\
\text { İşe dönüş-A: \%85/B: \%38 } \\
\text { Komplikasyonlar ve işe geri } \\
\text { dönme sürelerinde ise fark } \\
\text { gözlenmedi. }\end{array}$ & $\begin{array}{l}\text { Lokal Kifoz } \\
\text {-A: } 16,8^{\circ} \text { 'den } 8,6^{\circ} \text { 'ye azalma } \\
\text {-B: } 15,7^{\circ} \text { 'den } 19,8^{\circ} \text { 'ye artma } \\
\text { Torakolomber Kifoz } \\
\text {-A: } 10,9^{\circ} \text { 'den } 8,4^{\circ} \text { 'ye azalma } \\
\text {-B: } 13,1^{\circ} \text { den } 19,5 \text { ye artma } \\
\text { Kifoz deformitesindeki değişiklik } \\
\text { ile fonksiyonel iyileşme arasında } \\
\text { korelasyon gözlenmedi. }\end{array}$ \\
\hline $\begin{array}{l}\text { Abudou } \\
\text { ve ark.[18] } \\
2013\end{array}$ & 1 & $\begin{array}{l}\text { Sistematik } \\
\text { derleme }\end{array}$ & Bilinmiyor & $\begin{array}{l}\text { İki çalışma üzerinden } \\
\text { yapılmış. Siebanga ve ark. } \\
2006 \text { ve Wood ve ark. } \\
2003 \text {, nörolojik defisit } \\
\text { olmayan hastalar. }\end{array}$ & $\begin{array}{l}\text { Operasyon ve } \\
\text { konservatif tedavi } \\
\text { izlenmiş }\end{array}$ & $\begin{array}{l}\text { Derlemenin yapıldığı iki yayının } \\
\text { ağrı, fonksiyon ve işe dönüşs } \\
\text { sayıları hakkında birbirlerinin tam } \\
\text { tersi oranlar verdiği gözlenmiştir. } \\
\text { Net bir sonuç bildirilmemiştir. }\end{array}$ & $\begin{array}{l}\text { Derlemenin içerdiği yayınlarda } \\
\text { Sagittal kifoz deformite oluşumu } \\
\text { değerlendirilmemiştir. }\end{array}$ \\
\hline $\begin{array}{l}\text { Baily } \\
\text { ve ark. }{ }^{[19]} \\
2013\end{array}$ & 1 & $\begin{array}{l}\text { Ileriye dönük } \\
\text { Geriye dönük } \\
\text { Kohort } \\
96 \text { olgu }\end{array}$ & $2 Y_{l} l$ & $\begin{array}{l}\text { T11-L3 omurga kırıkları, } \\
\text { İzole AO A3 tip kırıklar, } \\
\text { kifoz derecesi }<35^{\circ}, \\
\text { nörolojik defisiti olmayan } \\
16-60 \text { yaş arası hastalar }\end{array}$ & $\begin{array}{l}\text { TLSO korse ile tedavi (A) } \\
\text { ve ortez olmadan tedavi } \\
\text { (B) değerlendirilmiş }\end{array}$ & $\begin{array}{l}\text { RMDQ-VAS-SF } 36 \text { skorlarında } \\
\text { farklılık izlenmemiş. }\end{array}$ & $\begin{array}{l}\text { Kifoz } \\
\text {-A: } 15^{\circ} \text { 'den } 22^{\circ} \text { ye artma } \\
\text {-B: } 14^{\circ} \text { 'den } 21^{\circ} \text { ye artma izlenmiş. } \\
\text { Anlamlı farklılık izlenmemiştir. }\end{array}$ \\
\hline $\begin{array}{l}\text { Wood } \\
\text { ve ark. }{ }^{[20]} \\
2003\end{array}$ & ॥ & $\begin{array}{l}\text { Ileriye dönük } \\
\text { Geriye dönük } \\
\text { Kohort } \\
47 \text { olgu }\end{array}$ & 3,7 YII & $\begin{array}{l}\text { T10-L2 tek seviye omurga } \\
\text { kırıkları değerlendirilmiş. } \\
\text { Posterior ligamentöz } \\
\text { kompleksin yaralandığı } \\
\text { olgular çalışma dışı } \\
\text { bırakılmış, } \\
18-60 \text { yaş arası hastalar }\end{array}$ & $\begin{array}{l}\text { Anterior ve posterior } \\
\text { enstrümantasyon ve } \\
\text { füzyon yapılan hastalar } \\
\text { (A) ile beden alçlama } \\
\text { ve Torakolumbosakral } \\
\text { ortez ile tedavi } \\
\text { edilen hastalar (B) } \\
\text { karşılaştırılmış }\end{array}$ & $\begin{array}{l}\text { VAS skor A: 3,3-B: 1,9 } \\
\text { Modifiye RMDQ skor A: 8,16-B 3,9 } \\
\text { ODI A: 20,75-B: 10,7 Anlamlı } \\
\text { fark gözlenmemiş. } \\
\text { SF36 ve fonksiyonel sonuçlar } \\
\text { B grubunda daha iyi iken } \\
\text { komplikasyonlar A grubunda } \\
\text { daha fazla gözlenmiş. }\end{array}$ & $\begin{array}{l}\text { Her iki grupta radyoljik sonuçlarda } \\
\text { farklılık gözlenmemiş. } \\
\text { Kifoz } \\
\text {-A: } 10,1^{\circ} \text { 'den } 13^{\circ} \text { 'ye artma } \\
\text {-B: } 11,3^{\circ} \text { 'den } 13,8^{\circ} \text { 'ye artma } \\
\text { Kırı̆ga bağlı kanal daralması } \\
\text {-A: } \% 39 \\
\text {-B: } \% 19 \\
\text { Oluşan kifoz deformitesi ile } \\
\text { fonksiyonel sonuçlar arasında } \\
\text { korelasyon gözlenmedi. }\end{array}$ \\
\hline $\begin{array}{l}\text { Stadhouder } \\
\text { ve ark. }{ }^{[16]} \\
2009\end{array}$ & ॥ & $\begin{array}{l}\text { Ileriye dönük } \\
\text { Geriye dönük } \\
\text { Kohort } \\
133 \text { olgu }\end{array}$ & En az 1 Yıl & $\begin{array}{l}\text { T3-L5 arası omurga } \\
\text { kırıkları, } \\
\text { AO A3 tip kırıklar }\end{array}$ & $\begin{array}{l}\text { Ortezleme }(A) \text { ve } \\
\text { vücut alçılama }(B) \\
\text { karşılaştırılmış }\end{array}$ & $\begin{array}{l}\text { VAS ve ODI skorlarında fark } \\
\text { gözlenmemiş. }\end{array}$ & $\begin{array}{l}\text { Kifoz açısında değişme } \\
\text { gözlenmemiş. }\end{array}$ \\
\hline $\begin{array}{l}\text { Gnanenthiran } \\
\text { ve ark.[12] } \\
2012\end{array}$ & $\|$ & $\begin{array}{l}\text { Sistematik } \\
\text { Derleme }\end{array}$ & Bilinmiyor & $\begin{array}{l}\text { Dört çalışma derlemeye } \\
\text { dahil edilmiş. } \\
\text { Siebenga ve ark. 2006, } \\
\text { Wood ve ark. 2003, } \\
\text { Shen ve ark. 2001, } \\
\text { Hitchon ve ark. } 1998\end{array}$ & $\begin{array}{l}\text { Operasyon ve } \\
\text { konservatif tedavi } \\
\text { izlenmiş }\end{array}$ & $\begin{array}{l}\text { Hastaların ağrılarında, RMDQ } \\
\text { skorlarında farklıık gözlenmemiş. } \\
\text { Cerrahi ile tedavi olanlarda } \\
\text { komplikayon oranlarının ve } \\
\text { maliyetin fazla olduğu gözlenmiş }\end{array}$ & $\begin{array}{l}\text { Kifoz deformitesi ile fonksiyonel } \\
\text { sonuçlar arasında korelasyon } \\
\text { gözlenmemiş }\end{array}$ \\
\hline $\begin{array}{l}\text { Shen } \\
\text { ve ark. }{ }^{[13]} \\
2001\end{array}$ & $\|$ & $\begin{array}{l}\text { Illeriye dönük } \\
\text { Karşılaştırmalı }\end{array}$ & $2 Y_{I} l$ & $\begin{array}{l}\text { T11-L2 arası tek seviye } \\
\text { omurga kırıkları, } \\
\text { 18-65 yaş arası }\end{array}$ & $\begin{array}{l}\text { Posterior } \\
\text { enstrümantasyon } \\
\text { uygulanmış hastalar } \\
\text { (A) ile hiperekstansiyon } \\
\text { ortezi uygulanmış } \\
\text { hastalar (B) } \\
\text { karşılaştırılmış. }\end{array}$ & $\begin{array}{l}\text { VAS skor-A: } 1,8 \text { B: } 1,5 \\
\text { Greenlough low-back skor-A: } \\
61 \text { B: } 65 \\
\text { Maliyet: Grup A da dört kat } \\
\text { fazla bulunmuş Hastanede yatış } \\
\text { süreleri ise her iki grupta benzer } \\
\text { bulunmuş. }\end{array}$ & $\begin{array}{l}\text { Kifoz } \\
\text {-A: } 23^{\circ} \text { 'den } 12^{\circ} \text { 'ye azalmış } \\
\text {-B: } 21^{\circ} \text { 'den } 24^{\circ} \text { 'ye artmış } \\
\text { Kifoz deformitesindeki değişme } \\
\text { ile fonksiyonel sonuçlar arasında } \\
\text { korelasyon gözlenmemiş. }\end{array}$ \\
\hline $\begin{array}{l}\text { Mohanty } \\
\text { ve ark. }{ }^{[17]} \\
2002\end{array}$ & II & $\begin{array}{l}\text { İeriye dönük } \\
\text { olgu serileri } \\
45 \text { olgu }\end{array}$ & $1 \mathrm{Y}, \mathrm{l}$ & $\begin{array}{l}17-60 \text { yaş arası } \\
\text { Torakolomber omurga } \\
\text { kırıkları }\end{array}$ & $\begin{array}{l}\text { Redüksiyon sonrası } \\
\text { polietilen korse ile } \\
\text { immobilizasyon ve } \\
\text { üç ay yatak istirahati } \\
\text { karşılaştırılmış. }\end{array}$ & $\begin{array}{l}\text { Kırı̆̆a bağıı kanal darlı̆̆ı } \\
\text { gelişmesi, nörolojik defisit } \\
\text { gelişmesi açısından iki grup } \\
\text { arasında anlamlı farklılık } \\
\text { gözlenmemiş. }\end{array}$ & \\
\hline $\begin{array}{l}\text { Hitchon } \\
\text { ve ark. }{ }^{[15]} \\
1998\end{array}$ & II & $\begin{array}{l}\text { Ileriye dönük } \\
\text { karşılaştırmalı } \\
68 \text { olgu }\end{array}$ & $0,8-1,8$ YII & T12-L2 omurga kırıkları & $\begin{array}{l}\text { Cerrahi ve ortezleme } \\
36 \text { olgu }(A) \text { ile yatak } \\
\text { istirahati ve ortezleme } \\
32 \text { olgu (B) }\end{array}$ & $\begin{array}{l}\text { Grup B de işe dönen hasta \%'si } \\
\text { daha çok, tedavi maliyeti daha } \\
\text { az iken hastanede yatış süresi her } \\
\text { iki grupta aynı gözlenmiştir. Her } \\
\text { iki grubun Frankel skorlarındaki } \\
\text { gelişme ise benzer bulunmuştur }\end{array}$ & $\begin{array}{l}\text { Kifoz } \\
\text {-A: } 12^{\circ} \text { 'den } 14,4^{\circ} \text { 'ye artmış } \\
\text {-B: } 5,6^{\circ} \text { 'den } 13,5^{\circ} \text { ye artmış }\end{array}$ \\
\hline
\end{tabular}


Tablo 2. "Oxford Centre of Evidence Based Medicine Levels of Evidence" tarafindan oluşturulan kanıt seviyeleri

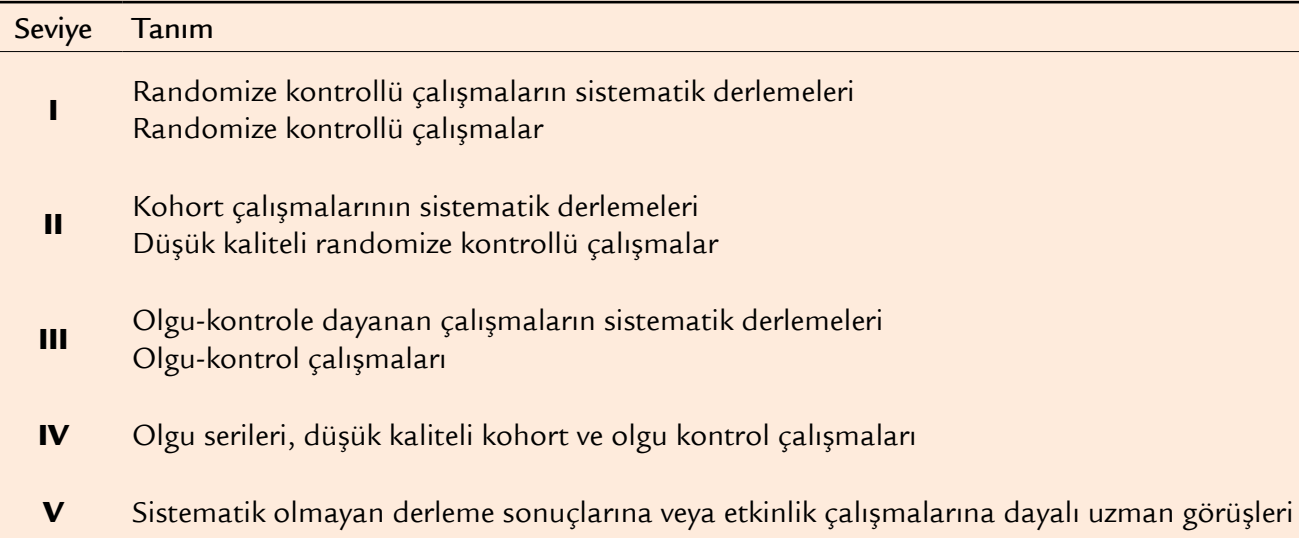

V Sistematik olmayan derleme sonuçlarına veya etkinlik çalışmalarına dayalı uzman görüşleri
Altı farklı anahtar kelime ile Pubmed'de yapılan aramalar sonrası çıkan çalışma sayısı
2758
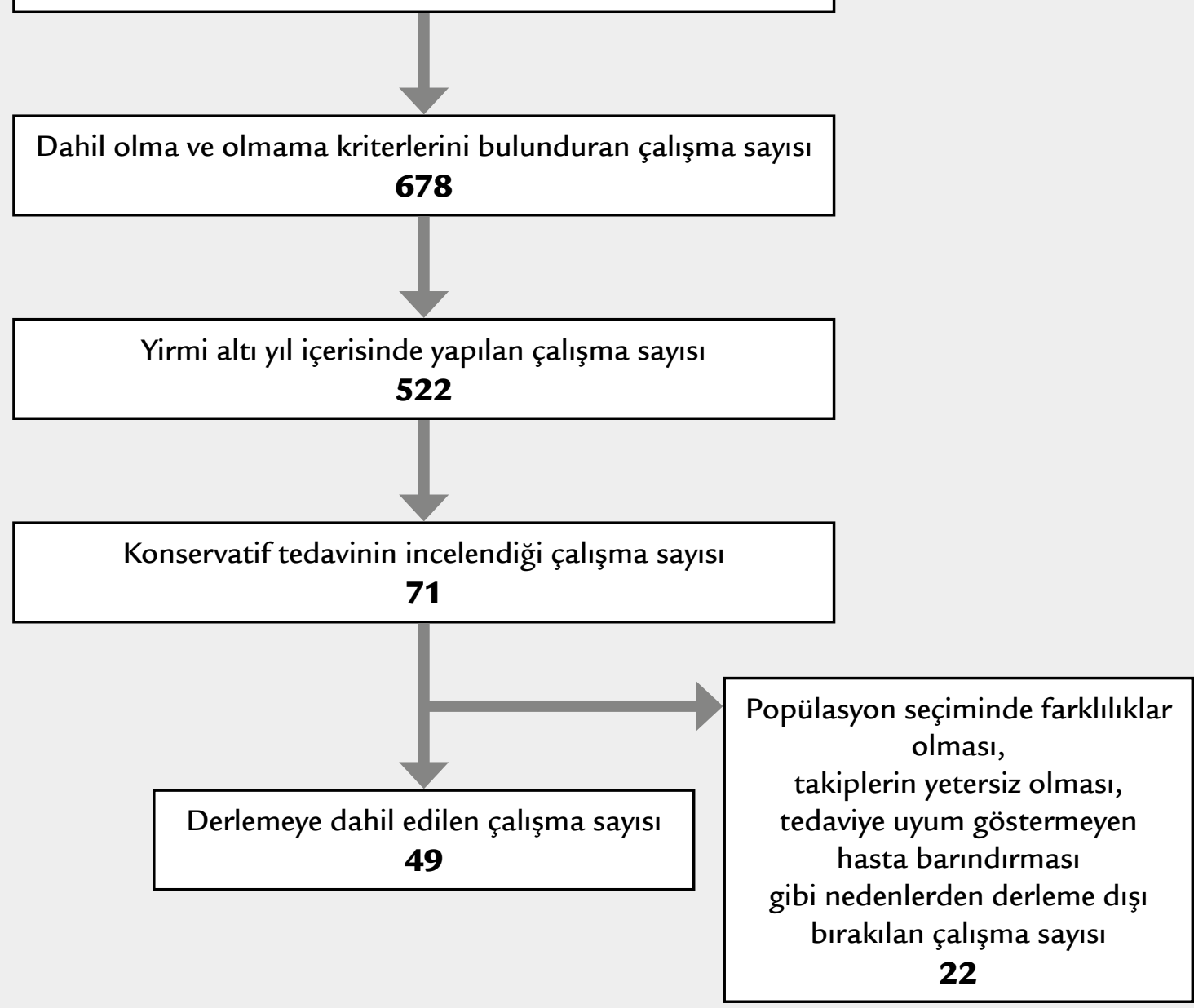

Şekil 1. Yirmi altı yıllık bir süreç içerisinde yazılmış çalışmaların derlemeye dahil olma süreci. 
hastaların genellikle uzun takipleri sonrası yapılmış olup hastaların sagittal düzlemde kifoz deformitelerinin takibe başlangıç ve takip sonu düzeyleri ele alınmıştır. Yayınların geneline bakıldığında kifozdaki artış cerrahi sonrası konservatif tedaviye göre daha az olmaktadır. Ancak, aradaki fark fonksiyonel sonuçlarla bağlantılı değildir. Dolayısı ile, radyolojik sonuçlar tedavi seçimini etkilememektedir. ${ }^{[5]}$

Siebanga ve ark. (2006) yılında 32 olgu ile ilgili ileriye dönük bir çalışma yapmış olup kısa segment posterior enstrümantasyon ve ortezlemeyi yalnızca ortezleme ile kıyaslamışlardır. Ortez olarak hiperekstansiyon Jewett brace tercih etmişlerdir. Hastaların seçiminde hastalarda nörolojik defisit olmamasına, kırıkların T10-L4 seviyesinde ve $A O$ sınıflamasına göre $A 1$ olmasına dikkat edilmiştir. Fonksiyonel sonuçlarda VAS ağrı skoru cerrahi ve ortezleme uygulananlarda 87 , yalnız ortezleme uygulananlarda 72, RMDQ skor ise 3,1'e 8,9 gözlenmiştir. İşe dönüş oranlarında bakıldığında; cerrahi geçiren hastalar çok yüksek oranda erken takip süresinde işe dönebilmiştir. Radyolojik olarak ise cerrahi ve ortezleme uygulananlar ile yalnız ortezleme uygulananlar kıyaslanmış; ilk grupta başlangıçtaki kırık bölgesindeki lokal kifoz açısı 16,8 iken, takiplerde 8,6; bölgesel kifoz ise 10,9'dan 8,4'e gelmiştir. İkinci grupta (yalnızca ortezleme yapılan grupta) ise lokal kifoz açısı 15,7'den 19,8'e; bölgesel kifoz açısı ise 13,1'den 19,5'e artmıştır. Kifozdaki artış ve azalışın fonksiyonel sonuçlarla uyuşmadığı ise yayında belirtilmiştir. ${ }^{[6-11]}$

Torakolomber omurga kırıkları hakkındaki yayınlar genel görüş olarak konservatif yaklaşım ve cerrahinin stabil kırıklarda benzer sonuçlar getirdiğinden bahsetse de yüksek kanıt seviyesine sahip başlıca yayınlardan bazıları $^{[5,12-15]}$ Gnanethiran ve ark.'nın (2012), Shen ve ark.'nın (2001) 80 olgu üzerinde yaptıkları çalışma, Hitchon ve ark.'nın 1998 yılında yaptığı 68 olgu üzerindeki çalışmalar gibi çalışmalar Siebanga ve ark.'nın vardığı sonucu destekler niteliktedir.

Nörolojik defisitli hastalar yayınlarda çalışma dışı bırakılmıştır. Çalışmaların bir yıllık takiplerinde ortaya çıkan ve üzerinde durulabilecek bir ayrıntı ise takiplerde ortaya çıkan nörolojik muayenedeki bozulmadır. Hitchon ve ark.'nın Seviye II çalışmasında nörolojik durumdaki bozulma oranlarında cerrahi veya konservatif tedavide bir fark olmadığı belirtilmektedir. Yaygın görüş ise cerrahi ile yapılan spinal dekompresyonun ileride gelişecek nörolojik durumdaki bozulmayı da engelleyeceği yönündedir.

\section{TARTIŞMA}

Nörolojik defisit gelişebilme olasılığı, geçmeyen ağrılar, işe dönüş oranının düşük ve işe dönüşün geç sürede olması konservatif tedaviden uzaklaştırırken, omurga cerrahisinin riskli bir bölgede oluşması, geri dönüşü zor komplikasyonlar gelişebilmesi tedavi seçiminde cerrahiden uzaklaştıran nedenlerdir. Sonuç olarak tedaviye yaklaşım ve tedavinin başarısı cerrahın tecrübesine, kişisel görüş ve becerisine bağlıdır. Çok merkezli yapılmayan çalışmalarda sonuçlar tedavi şeklinin başarısından çok ilgilenen hekimin başarısını yansıtabilir.

Konservatif yaklaşımın sunduğu avantajlar karşısında cerrahi yaklaşım oldukça fazla çekinceler yaratmaktadır. Bu ise yayınların objektif olmasını bir ölçüde engellemektedir. Konservatif yaklaşım cerrahiye göre çok az maliyetlidir ve komplikasyonları cerrahi kadar korkutucu değildir. Dezavantaj olarak ise konservatif yaklaşım hareketi engellemeye dayanmakta ve bu hastalar için ikincil bir travmaya yol açmaktadır. Hareketin hangi düzlemlerde kısıtlanması gerektiği konusunda ise bir görüş birliği sağlanamamıştır. Dolayısıyla, ortez seçiminde de çeşitli fikir ayrılıkları bulunmaktadır. Yaygın görüş̧; ortezlerin getirdiği tedavi başarısında ortez seçiminin etkisinin belirleyici olmadığı şeklindedir. Yalnızca iki adet Seviye II yayın ortez çeşitlerini değerlendirmiştir. ${ }^{[16]}$ Stadhouder ve ark.'nın vücut alçılama ve ortezleme üzerine yaptığı 2009 tarihli T3-L5 vertebra fraktürlerini içeren 133 olgu içeren Seviye II yayınında, bu iki konservatif yaklaşım üzerinde fonksiyonel olarak VAS ve ODI skorlarında, radyolojik olarak ise kifoz açısında herhangi bir fark olmadığı belirtilmiştir. Konservatif yaklaşımın nasıl olacağı konusunda fikir ayrılıkları doğru konservatif yaklaşımın uygulanıp uygulanmadığı sorusuna da neden olmaktadır.

Bir diğer tartışma konusu ise kırık sınıflamasının nasıl belirlendiğine ve görüntüleme olarak hangi tekniğin seçileceği yönündedir. Çalışmaların çoğu MR veya bilgisayarlı tomografi (BT) görüntüleme zorunluluğu olmadan, bu görüntülemeleri kriter kabul etmeden yapılmıştır. Hangi görüntüleme yöntemiyle kırıklara sınıflandırma yapılacağı konusu açıklığa kavuşmamıştır. Sonuç olarak; yayınlarda stabil kırık seçiminin net olarak yapılmış olup olmadığı net değildir.

Yayınların genelinde hastaların sosyoekonomik ve kültürel düzeylerine, eğitim düzeylerine değinilmemiştir. Ancak, konservatif tedaviler uzun süreli ve uyum süreci açısından zor tedavi şekilleridir ve pratikte hastalar konservatif tedaviyi önerildiği şekilde uygulamamaktadırlar. Bu da tedavilerin başarı oranlarını değiştirmektedir. Ayrıca, bu durum yapılan çalışmaların yapıldığı yere göre değişkenlik arz edeceğini de göstermektedir.

Ortezlemelerde kullanılan malzemeler, ortezlemelerin nasıl yapılacağı, ortezlemeyi kimin yapacağı tartışma konusudur. Dolasıyla, uygulanan ortezlemenin başarılı ve standart olup olmadığı tartışmalıdır. 
Ortezlemede gelişmeler plastik hammadelerin yaygınlaşması ve ortezleme konusunda kullanımının çeşitlendirilmesi ile hızlı şekilde sağlanmıştır. Ancak, bu durum ekonomik olarak çeşitlilik yaratmaktadır. Üretilen ortezin standart kalıplar ile üretilmiş olması, hastaya özel, el yapımı üretilmiş olması, seçilen konservatif tedavide ekonomik tercihlerin göz önüne alınıp alınmadığı yayınlarda bahsedilmese de tedavi başarısında büyük rol oynamaktadır. Ayrıca, standart bir konservatif tedaviden de söz edilemeyeceğini göstermektedir.

Nörolojik defisit konservatif yaklaşımlar için kesin kontrendikasyon oluşturmamaktadır. Mohanty ve ark. 2002 yılında 45 olguluk bir seride, kırıklara bağlı kanal darlığının nörolojik defisit gelişmesi ve nörolojik iyileşmenin üzerine etkisi olmadığını belirtmişlerdir. ${ }^{[17]}$ Bu da, konservatif tedavinin nörolojik defisiti olan torakolomber omurga kırıklarında etkisini tartışılır hale getirmektedir. Ancak, nörolojik defisitli hastalarda konservatif yaklaşımların sonuçları üzerine hazırlanmış çok az yayın bulunmaktadır. Bu da, nörolojik defisitlerin neden genel olarak çalışma dışı bırakıldığını ve cerrahi seçeneğinin ilk seçenek olarak seçildiğini açıklar.

Seçilen yayınların pek çoğu iki yıldan daha az süren takipleri içermektedir. Dolayısıyla, seçilen tedavinin uzun süreli sonuçları hakkında yeterince bilgi mevcut değildir. Altın standart tedavi seçeneğinin araştırılabilmesi, tedavi için doğru stratejinin belirlenebilmesi için halen kanıt seviyesi yüksek, geniş kapsamlı ve uzun dönem sonuçları içeren çok sayıda yayına ihtiyaç duyulmaktadır.

\section{KAYNAKLAR}

1. Ohana N, Sheinis D, Rath E, Sasson A, Atar D. Is There a Need for Lumbar Orthosis in Mild Compression Fractures of the Thoracolumbar Spine? A Retrospective Study Comparing the Radiographic Results Between Early Ambulation With and Without Lumbar Orthosis. J Spinal Disord 2000;13(4):3058. Crossref

2. Aleem IS, Nassr A. Surgical Versus Non-surgical Treatment for Thoracolumbar Burst Fractures Without Neurological Deficit. Clin Orthop Relat Res 2015;474(3):619-24. Crossref

3. Bakhsheshian J, Dahdaleh NS, Fakurnejad S, Scheer JK, Smith ZA. Evidence-based management of traumatic thoracolumbar burst fractures: a systematic review of nonoperative management. Neurosurg Focus 2014;37(1):E1. Crossref

4. Ghobrial GM, Maulucci CM, Maltenfort M, Dalyai RT, Vaccaro AR, Fehlings MG, Street J, Arnold PM, Harrop JS. Operative and nonoperative adverse events in the management of traumatic fractures of the thoracolumbar spine: a systematic review. Neurosurg Focus 2014;37(1):E8. Crossref

5. Siebenga J, Leferink VJM, Segers MJM, Elzinga MJ, Bakker FC, Haarman HJThM, Rommens PM, Duis HJ, Patka P. Treatment of traumatic thoracolumbar spine fractures: a multicenter prospective randomized study of operative versus nonsurgical treatment. Spine (Phila Pa 1976) 2006;31(25):2881-90. Crossref
6. Mohamadi A, Googanian A, Ahmadi A, Kamali A. Comparison of surgical or nonsurgical treatment outcomes in patients with thoracolumbar fracture with Score 4 of TLICS. Medicine 2018;97(6):e9842. Crossref

7. Nataraj A, Jack AS, Ihsanullah I, Nomani S, Kortbeek F, Fox R. Outcomes in Thoracolumbar Burst Fractures with a Thoracolumbar Injury Classification Score (TLICS) of 4 Treated With Surgery Versus Initial Conservative Management. Clin Spine Surg 2018;31(6):E317-21. Crossref

8. Kim BG, Dan JM, Shin DE. Treatment of Thoracolumbar Fracture.Asian Spine J 2015;9(1):133-46. Crossref

9. Giele BM, Wiertsema $\mathrm{SH}$, Beelen $\mathrm{A}$, van der Schaaf M, Lucas $C$, Been HD, Bramer JAM. No evidence for the effectiveness of bracing in patients with thoracolumbar fractures $A$ systematic review. Acta Orthopaedica 2009;80(2):226-32. Crossref

10. An HS, Simpson JM, Ebraheim NA, Jackson WT, Moore J, O'Malley NP. Low lumbar burst fractures: comparison between conservative and surgical treatments. Orthopedics 1992;15(3):367-73.

11. Ağuş $H$, Kayali $C$, Arslantaş $M$. Nonoperative treatment of burst-type thoracolumbar vertebra fractures: clinical and radiological results of 29 patients. Eur Spine J 2005;14(6):536-40. Crossref

12. Gnanenthiran SR, Adie S, Harris IA. Nonoperative versus operative treatment for thoracolumbar burst fractures without neurologic deficit: a meta-analysis. Clin Orthop Relat Res 2012;470(2):567-77. Crossref

13. Shen WJ, Liu TJ, Shen YS. Nonoperative treatment versus posterior fixation for thoracolumbar junction burst fractures without neurologic deficit. Spine (Phila Pa 1976) 2001;26(9):1038-45. Crossref

14. Shen WJ, Shen YS. Nonsurgical treatment of three-column thoracolumbar junction burst fractures without neurologic deficit. Spine (Phila Pa 1976) 1999;24(4):412-5. Crossref

15. Hitchon PW, Torner JC, Haddad SF, Follett KA. Management options in thoracolumbar burst fractures. Surg Neurol 1998;49(6):619-27. Crossref

16. Stadhouder A, Buskens E, Vergroesen DA, Fidler MW, de Nies $F$, Öner FC. Nonoperative treatment of thoracic and lumbar spine fractures: a prospective randomized study of different treatment options. J Orthop Trauma 2009;23(8):588-94. Crossref

17. Mohanty SP, Venkatram N. Does neurological recovery in thoracolumbar and lumbar burst fractures depend on the extent of canal compromise? Spinal Cord 2002;40(6):295-9. Crossref

18. Abudou $M$, Chen $X$, Kong $X$, Wu T. Surgical versus nonsurgical treatment for thoracolumbar burst fractures without neurological deficit. Cochrane Database Syst Rev 2013. CD005079. Crossref

19. Bailey CS, Urquhart JC, Dvorak MF, Nadeau M, Boyd MC, Thomas KC, Kwon BK, Gurr KR, Bailey SI, Fisher CG. Orthosis versus no orthosis for the treatment of thoracolumbar burst fractures without neurologic injury: a multicenter prospective randomized equivalence trial. Spine J 2013;14(11):2557-64.

20. Wood K, Buttermann G, Mehbod A, Garvey T, Jhanjee R, Sechriest V. Operative compared with nonoperative treatment of a thoracolumbar burst fracture without neurological deficit. A prospective, randomized study. J Bone Joint Surg Am 2003;85A(5):773-81, (Erratum in: J Bone Joint Surg Am 2004;86$A(6): 1283$. Butterman, $G$ [corrected to Buttermann, G]) 